\title{
Komparasi Prestasi Belajar Matematika antara Siswa yang diajar menggunakan Model Pembelajaran Kooperatif tipe Snowball Throwing dan Tipe Make a Match di Kelas VII SMP
}

\author{
Tahir ${ }^{1, a)}$, Hamzah Upu ${ }^{1}$ dan Suradi ${ }^{1}$ \\ ${ }^{1}$ Jurusan Matematika FMIPA Universitas Negeri Makassar \\ a) nurfathirah.tahir@gmail.com
}

\begin{abstract}
Abstrak. Penelitian ini dilakukan untuk mengetahui perbandingan prestasi belajar siswa melalui penerapan model kooperatif tipe Snowball Throwing dan Make a Match dalam pembelajaran matematika. Penelitian ini adalah penelitian eksperimen yang melibatkan dua kelompok yang diberi perlakuan dengan sampel penelitian sebanyak 47 siswa dari kelas VII SMP di Sinjai yang dipilih dengan menggunakan teknik double cluster random sampling. Teknik pengumpulan data menggunakan instrumen: (1) lembar observasi keterlaksanaan model pembelajaran dan (2) tes hasil belajar matematika. Data dianalisis dengan statistik deskriptif dan statistik inferensial dengan analisis uji-t. Hasil penelitian menunjukkan bahwa: (1) Skor rara-rata prestasi belajar matematika dari 25 siswa setelah pembelajaran menggunakan model pembelajaran kooperatif tipe Snowball Throwing yaitu 4\% berada pada kategori sangat rendah, 40\% pada kategori sedang, 36\% pada kategori tinggi dan 20\% pada kategori sangat tinggi. (2) Skor rara-rata prestasi belajar matematika dari 22 siswa setelah pembelajaran menggunakan model pembelajaran kooperatif tipe Make a Match yaitu 9,09\% berada pada kategori sangat rendah, 4,54\% pada kategori rendah, 50\% pada kategori sedang serta 18,18\% masingmasing pada kategori tinggi dan sangat tinggi. (3) Tidak terdapat perbedaan yang signifikan antara prestasi siswa setelah menerapkan model pembelajaran kooperatif tipe snowball throwing dan tipe make a match di Kelas VII SMP dengan materi Bangun Datar Segiempat.
\end{abstract}

Kata Kunci: Prestasi belajar, pembelajaran matematika, model pembelajaran kooperatif, snowball throwing, make a match

\begin{abstract}
This research was conducted to determine the comparison of student learning achievement through the application of the cooperative model type Snowball Throwing and Make a Match in mathematics learning. This research was an experimental research involving two groups treated with research sample of 47 students from class VII SMP Sinjai selected by using the double cluster random sampling technique. Techniques of collecting data using instruments: (1) observation sheet of learning model implementation and (2) tests of mathematics learning result.Data were analyzed with descriptive statistics and inferential statistics with t-test analysis. The results showed that : (1) Average score of mathematics learning achievement of 25 students after learning using the Snowball Throwing type of cooperative learning model which is 4\% in the very low category, $40 \%$ in the medium category, $36 \%$ in the high category and $20 \%$ in the very high category. (2) The average score of mathematics learning achievement from 22 students after learning using the Make a Match type of learning model is $9.09 \%$ in the very low category, $4.54 \%$ in the low category, $50 \%$ in the medium category and $18,18 \%$ in the high and very high categories. (3) There is no significant difference between student achievement after applying the snowball throwing type cooperative learning model and the type of make a match in Class VII Junior High School with the Rectangular Build Up material.
\end{abstract}

Keywords: Learning achievement, mathematics learning, cooperative learning model, snowball throwing, make a match. 


\section{PENDAHULUAN}

Siswa dituntut aktif selama proses pembelajaran. Dengan siswa aktif bertanya, mengemukakan ide, serta banyak berlatih mengerjakan soal-soal matematika dapat mempermudah siswa menerima materi yang diajarkan oleh guru. Karena konsep-konsep dasar dalam pembelajaran matematika sangat diperlukan, mengingat itu saling terkait antara materi satu dengan materi lainnya. Oleh karena itu, penggunaan model pembelajaran yang lebih menarik, bervariasi dan disukai oleh siswa diperlukan dalam menumbuhkan keinginan mereka untuk mengikuti proses pembelajaran.

Menurut Slavin (Isjoni, 2007), Pembelajaran kooperatif adalah suatu model pembelajaran dimana siswa belajar dan bekerja dalam kelompok-kelompok kecil secara kolaboratif yang anggotanya 4-6 orang dengan struktur kelompok heterogen. Karena dalam model pembelajaran kooperatif ini, siswa akan berinteraksi dengan sesama teman kelompok, sehingga memungkinkan terjadinya pertukaran pendapat. Model pembelajaran kooperatif sangat membantu tugas dari seorang guru dalam menyampaikan materi yang akan dibawakan karena pembelajaran kooperatif mengharuskan melakukan interaksi antar teman sejawatnya untuk melakukan atau menyelesaikan tugas yang diberikan oleh guru

Model pembelajaran kooperatif tipe snowball throwing dan tipe make a match merupakan 2 tipe dari banyaknya tipe model pembelajaran kooperatif yang melibatkan siswa secara aktif. Kedua tipe tersebut menggunakan strategi permainan dalam proses pembelajarannya. Hal ini dapat membantu meningkatkan motivasi dan prestasi belajar matematika siswa.

Model pembelajaran kooperatif tipe snowball throwing dapat diartikan sebagai model pembelajaran dengan menggunakan pertanyaan dari kertas yang digulung bulat berbentuk bola kemudian dilemparkan secara bergilir diantara siswa pada kelompok lain. Model pembelajaran Snowball Throwing melatih murid untuk lebih tanggap menerima pesan dari orang lain, dan menyampaikan pesan tersebut kepada temannya dalam satu kelompok (Devi, 2011). Lemparan pertanyaan tidak menggunakan tongkat seperti model pembelajaran Talking Stik akan tetapi menggunakan kertas berisi pertanyaan yang diremas menjadi sebuah bola kertas lalu dilemparlemparkan kepada murid lain. Murid yang mendapat bola kertas lalu membuka dan menjawab pertanyaannya. Tujuan pembelajaran Snowball Throwing yaitu melatih murid untuk mendengarkan pendapat orang lain, melatih kreativitas dan imajinasi murid dalam membuat pertanyaan, serta memacu murid untuk bekerjasama, saling membantu, serta aktif dalam pembelajaran (Asrori, 2010). Beberapa hasil penelitian terkait model pembelajaran kooperatif tipe snowball throwing menyimpulkan bahwa model pembelajaran tipe snowball throwing dapat meningkatkan prestasi belajar matematika siswa (Hardianto, 2015; Alamuddin \& Munawaroh, 2014).

Model pembelajaran kooperatif tipe make a match merupakan pembelajaran dengan membagi siswa ke dalam kelompok kecil dan mencari pasangan. Model pembelajaran make and match adalah sistem pembelajaran yang mengutamakan penanaman kemampuan sosial terutama kemampuan bekerja sama, kemampuan berinteraksi disamping kemampuan berpikir cepat melalui permainan mencari pasangan dengan dibantu kartu (Wahab, 2007). Make a match yaitu teknik dimana siswa mencari pasangan sendiri sambil belajar mengenal suatu konsep atau topik dalam suasana yang menyenangkan (Huda, 2011). Hal senada disebutkan oleh Suyatno (2009) mengungkapkan bahwa model make and match adalah model pembelajaran dimana guru menyiapkan kartu yang berisi soal atau permasalahan dan menyiapkan kartu jawaban kemudian siswa mencari pasangan kartunya. Beberapa penelitian yang terkait dengan model pembelajaran kooperatif tipe make a match, menyimpulkan bahwa model pembelajaran tipe make a match dapat meningkatkan prestasi belajar matematika siswa (Sutikno, 2016; Nursinta, 2018; Puspitaningrum, 2018). 


\section{METODE PENELITIAN}

Penelitian ini merupakan penelitian kuantitatif quasi experiment atau eksperimen semu. Penelitian ini dilaksanakan di salah satu SMP Negeri di Kabupaten Sinjai Sulawesi Selatan. Populasi dalam penelitian ini adalah siswa kelas VIII SMP yang terdiri dari tujuh kelas. Sampel dalam penelitian ini adalah dua kelas eksperimen dimana kelas eksperimen I terdiri dari 25 siswa dan diterapkan Model pembelajaran kooperatif tipe snowball throwing. Sedangkan kelas eksperimen II terdiri dari 22 siswa dan diterapkan pembelajaran kooperatif tipe make a match.

Instrumen yang digunakan yaitu lembar observasi keterlaksanaan pembelajaran dan tes prestasi belajar siswa. Adapun kategori keterlaksanaan proses pembelajaran dan kategori skor tes prestasi belajar dapat dilihat pada Tabel 1 dan Tabel 2.

TABEL 1. Kategori Keterlaksanaan Model Pembelajaran

\begin{tabular}{cc}
\hline Skor Rata-Rata & Kategori \\
\hline $1,0<\bar{x} \leq 1,4$ & Tidak Terlaksana \\
$1,5<\bar{x} \leq 2,4$ & Kurang Terlaksana \\
$2,5<\bar{x} \leq 3,4$ & Terlaksana dengan Baik \\
$3,5<\bar{x} \leq 4,0$ & Terlaksana dengan Sangat Baik \\
\hline & Sumber : (Tenritte,
\end{tabular}

2016)

TABEL 2. Kategori Skor Tes Prestasi Belajar

\begin{tabular}{cc}
\hline Interval Nilai & Kategori \\
\hline $90-100$ & Sangat Tinggi \\
$80-89$ & Tinggi \\
$65-79$ & Sedang \\
$55-64$ & Rendah \\
$0-54$ & Sangat Rendah \\
\hline
\end{tabular}

Sumber: (Tenritte, 2016)

Adapun teknik analisis dalam penelitian ini adalah analisis Statistik Deskriptif dan Inferensial. Hasil analisis deskriptif meliputi penyajian data melalui tabel, mean, modus, standar deviasi dan perhitungan persentase. Analisis statistik inferensial menggunakan untuk uji hipotesis penelitian. Metode analisis yang digunakan dalam penelitian ini adalah analisis kuantitatif dengan analisis regresi linear berganda (multiple linear analysis) pada taraf kepercayaan 95\% $(\alpha=0,05)$.

\section{HASIL DAN PEMBAHASAN}

Tabel 3 memperlihatkan bahwa hasil observasi keterlaksanaan model pembelajaran snowball throwing dan make a match terlaksana dengan baik. Adapun selisih rata-rata keterlaksanaan kedua model tersebut hanya 0,01 adalah angka kecil yang mengindikasikan bahwa keterlaksanaan kedua model dianggap sama sehingga layak dibandingkan.

TABEL 3. Rekapitulasi Hasil Observasi Keterlaksanaan

\begin{tabular}{ccc}
\hline $\begin{array}{c}\text { Keterlaksanaan } \\
\text { Model }\end{array}$ & $\begin{array}{c}\text { Skor } \\
\text { rata- } \\
\text { rata }\end{array}$ & Klasifikasi \\
\hline $\begin{array}{c}\text { Snowball } \\
\text { Throwing }\end{array}$ & 3,65 & $\begin{array}{c}\text { Terlaksana } \\
\text { dengan }\end{array}$ \\
Make a Match & 3,64 & $\begin{array}{c}\text { Sangat } \\
\text { Baik } \\
\text { Terlaksana } \\
\text { dengan }\end{array}$ \\
\hline
\end{tabular}




\section{Sangat \\ Baik}

Tabel 4 memperlihatkan bahwa rata-rata skor prestasi belajar belajar matematika pada model pembelajaran snowball throwing dan make a match masing-masing berada pada kategori tinggi dan sedang. Perbedaan nilai rata-rata pada kedua tipe model pembelajaran kooperatif tersebut menunjukkan bahwa terdapat perbedaan antara prestasi belajar siswa pada model kooperatif tipe snowball throwing dengan tipe make a match. Setelah melihat hasil perbandingan kedua model, dapat dikatakan bahwa model kooperatif tipe snowball throwing lebih baik dibandingkan tipe make a match.

TABEL 4. Rekapitulasi Hasil Tes Prestasi Belajar Siswa

\begin{tabular}{ccc}
\hline Keterlaksanaan Model & $\begin{array}{c}\text { Skor rata- } \\
\text { rata }\end{array}$ & Kategori \\
\hline Snowball Throwing & 82,35 & Tinggi \\
Make a Match & 78,01 & Sedang \\
\hline
\end{tabular}

Tabel 5 memperlihatkan hasil output uji normalitas varians dengan menggunakan uji Kolmogorov-Smirnov, menunjukkan nilai signifikan untuk kedua tipe model pembelajaran kooperatif tersebut lebih dari 0,05 , maka dapat dikatakan bahwa model pembelajaran kooperatif tipe snowball throwing dan tipe make a match berdistribusi normal.

TABEL 5. Hasil output Uji Normalitas

\begin{tabular}{ccc}
\hline Model Pembelajaran & Nilai Signifikan & Klasifikasi \\
\hline Snowball Throwing & 0,200 & Berdistibusi Normal \\
Make a Match & 0,200 & Berdistribusi Normal
\end{tabular}

Hasil output uji homogenitas dengan menggunakan SPSS menunjukkan nilai signifikan untuk data posttest adalah 0,387. Karena nilai signifikansi kedua kelas lebih dari 0,05, maka dapat dikatakan bahwa variansi kelas data sama.

\section{Uji Perbandingan}

Uji hipotesis yang dilakukan dengan uji-t melalui program SPSS 20.0 menggunakan Independent Sample Test dengan asumsi kedua varians normal dan taraf signifikan 0,05, diperoleh nilai sig.(2-tailed) adalah 0,186 >0,05. Dengan demikian dapat disimpulkan bahwa $\mathrm{H}_{0}$ diterima. Dengan kata lain, peningkatan prestasi belajar penerapan pembelajaran matematika dengan model kooperatif tipe Snowball Throwing tidak memiliki perbedaan dengan tipe Make a Match dalam mengajarkan materi Bangun datar segiempat di kelas VII SMP.

\section{KESIMPULAN}

Pembelajaran dengan menggunakan Model Pembelajaran Kooperatif tipe Snowball Throwing dan tipe Make a Match materi Bangun datar segiempat di kelas VII SMP terlaksana dengan kategori sangat baik. Pembelajaran dengan menggunakan Model Pembelajaran Kooperatif tipe Snowball Throwing lebih baik daripada tipe Make a Match di Kelas VII SMP. Setelah mengetahui hasil penelitian dengan membandingkan kedua model tersebut, disarankan penelitian lebih lanjut dalam penerapan Model Pembelajaran Kooperatif tipe Snowball Throwing dan tipe Make a Match ditinjau dari motivasi atau minat belajar siswa. 


\section{DAFTAR PUSTAKA}

Alamuddin, A., \& Munawaroh, M. (2014). Pengaruh Penerapan Model Pembelajaran Snowball Throwing terhadap Hasil Belajar Matematika Siswa dengan Pokok Bahasan Relasi dan Fungsi. EduMa, $3(2)$.

Asrori. (2010). Pengertian Pendekatan, Strategi, Metode, Teknik dan Model Pembelajaran. Jakarta: PT Bumi Aksara.

Devi, S. (2010). Peningkatan Prestasi Belajar Siswa melalui Model Pembelajaran Kooperatif Tipe Snowball Throwing dengan Memanfaatkan Media Berbasis Animasi Pada Mata Pelajaran Pemrograman Dasarpada Kelas X SMK Negeri 1 Magelang. (Skripsi). Magelang: Program Studi Pendidikan Matematika FMIPA Universitas Kristen Satya Wacana.

Hardianto. (2015). Pengaruh Model Pembelajaran Kooperatif Tipe Snowball Throwing terhadap Prestasi Belajar Matematika Siswa. Ekuivalen-Pendidikan Matematika, 15. 1.

Huda, M. (2011). Cooperative Learning. Yogyakarta: Pustaka Pelajar.

Isjoni. (2007). Cooperative Learning: Efektivitas Pembelajaran Kelompok. Bandung: Alfabeta.

Narsinta, D. H. (2018). Pengaruh Penerapan Model Pembelajaran Kooperatif tipe Make a Match terhadap Kemampuan Mengaplikasikan dan Menganalisis Siswa Kelas V SDN Jetis Bantul Yogyakarta. (Skripsi tidak dipublikasikan). Universitas Sanata Dharma. Yogyakarta.

Puspitaningrum, F. (2018). Pengaruh Model Pembelajaran Kooperatif tipe Make a Match terhadap Hasil Belajar Matematika Siswa Kelas V SD Negeri 2 Branti Raya. (Skripsi tidak dipublikasikan). Universitas Lampung. Lampung.

Sutikno. (2016). Pengaruh Model Pembelajaran Kooperatif Tipe Make A Match terhadap Prestasi Belajar Matematika Siswa. (Skripsi). Yogyakarta: Jurusan Matematika FMIPA Universitas Negeri Yogyakarta.

Suyatno. (2009). Menjelajah Pembelajaran Inofatif. Sidoarjo: Masmedia Buana Pusaka.

Tenritte, A. (2016). Pengaruh Model Pembelajaran Terhadap Kemampuan Pemahaman Konsep Matematika. (Skripsi tidak dipublikasikan). Makassar: FMIPA UNM.

Wahab. (2007). Metode dan Model-Model Mengajar. Bandung: Alfabeta. 